\title{
Prevalence of Adhesion Genes fnbA \& fnbB of Staphylococcus aureus Isolated from Dental Patients Attending Dentistry Department of Tehsil Headquarter Hospital Pasrur, Pakistan
}

\author{
Muhammad Danish Mehmood, Huma Anwar ul-Haq, Khushbu Farva, Zuhaib Farooq, Gul \\ Muhammad Shaikh, Muhammad Usman Ghani, and Verda Naeem
}

\section{ABSTRACT}

Introduction: The present study was intended to isolate, characterize and investigate the prevalence of virulence genes encoding fibronectin $(f n b \mathrm{~A}$ and $f n b B)$ adhesive molecules of $S$. aureus from dental patients attending outpatient department of THQ Hospital PasrSur. Methodology: A total of 100 oral samples were collected from dental patients, pure cultures was segregated and identified through conventional microbiological methods to evaluate the prevalence of $S$. aureus. Isolates were further characterized by using specific primers for genotype $f \boldsymbol{n} b \mathrm{~A}$ and $\boldsymbol{f} \boldsymbol{n} \boldsymbol{b B}$. Results: Results of the study declared that 68 samples were positive $(68 \%)$ for staphylococcus aureus on the basis of growth on selective media and appearance of typical colonies supported by gram staining. These gram-positive staphylococci were positive $(86.7 \%)$ in coagulase and catalase testing. The results of polymerase chain reaction (PCR) revealed that $47(69.1 \%)$ and $23(33.8 \%)$ isolates showed amplification with type specific primer 23Sr RNA and $N U C$ gene respectively. Furthermore, $f n b A$ and $f n b B$ type specific genes of $S$. aureus did not show any amplification in PCR reaction.Conclusion: Irrespectively the data in the present study showed the prevalence of $S$. aureus is significantly high in males and of age group of 20-40 years but no positive result was found for prevalence of $f n b \mathrm{~A}$ and $f n b B$ genes. All the $S$. aureus isolates were highly sensitive to vancomycin, linezolid and clindamycin.

Keywords: Staphylococcus aureus, fnbA, fnbB, Polymerase chain reaction $(\mathrm{PCR})$
Published Online: July 06, 2020

ISSN: $2684-4443$

DOI :10.24018/ejdent.2020.1.4.6

Muhammad Danish Mehmood*, Ottoman Pharma, Pakistan. (drdanishmehmood@gmail.com) *Corresponding Author

Huma Anwar UL-Haq,

Ottoman Pharma, Pakistan.

(huma.anwar16@gmail.com)

\section{Khushbu Farva,}

Shara medical College, Narowal, Pakistan.

(drkhushbufarva @gmail.com)

\section{Zuhaib Farooq,}

Surgident Executive Dental Clinic, Pakistan.

(surgidentexective @gmail.com)

Gul Muhammad Shaikh,

Shahida Islam Medica \& Dental

College, Pakistan.

(Shaikhgul25@gmail.com)

Muhammad Usman Ghani
Ottoman Pharma, Pakistan.
(u.kashmiri@gmail.com)
Verda Naeem,
Rawal medical and Dental College,
Pakistan.
(farhanafzal27@gmail.com)

\section{INTRODUCTION}

The normal oral flora comprises a diverse group of microorganisms, including bacteria, fungi, protozoa and possibly even viruses. More than 300 species inhibit the oral cavity of which about 30 are found routinely and account for the majority of the cultivable strains [1]. The presence of staphylococcus species as a component of the resident oral flora is controversial but surprisingly there have been relatively few detailed studies of distribution of staphylococci in the mouth. Some infections in the circum-oral region are caused, at least in part by S. aureus. These include angular cheilitis some endodontic infections osteomyelitis of the jaw parotitis and more recently recognized a form of oral mucositis in elderly $[2,3,4,5,6]$. Interestingly, there is now a growing body of evidence to suggest that staphylococci can be isolated frequently from the oral cavity of particular patient groups such as children, the elderly and some groups with systemic disease such as the terminally ill [7, 8, 9]. Those with rheumatoid arthritis and patients with hematological malignancies $[10,11]$. There is also the potential for dissemination of oral staphylococcal strains to re-colonies other body sites or as a source of cross-infection to other patients.

Staphylococcus aureus is a type of staphylococcus genus, which is made of Gram-positive bacteria and its diameter is 0.5-1.5 [12]. Staphylococcus aureus is known as one of the 
most diseases causing pathogen in humans both in community and hospital environments. It was firstly identified in 1884, when Friedrick Julius Rosenbach separated it from Staphylococcus abacus now it is known as known as Staphylococcus epidermidis. It often colonizes the skin and mucous membranes of normal individuals, in particular the anterior nares [13]. The presences of colonies represent more amount of risk of infection by giving a storage from which bacteria are launched when the host defense is weak [14]. Due to its disease spreading quality of S. aureus and the increasing resistances against antibiotic these bacteria have become the most studied staphylococcal species. Staphylococcus aureus can cause many of infections in humans, and it is ranging from infections of the skin to severe systemic infections. A plenty of illness can be caused by Staphylococcal infection (Table I) are given below.

\section{TABLE 1: STAPHYLOCOCCUS AUREUS RELATED INFECTIONS IN} HUMANS

\section{Types of diseases}

Skin related
Deep-seated
Food borne
Toxin
mediated

Impetigo, boils, furuncles, folliculitis, abscesses. Endocarditis, pneumonia, osteomoielitis, meningitis Bacteremia, sepsis, Food poisoning, toxic shock syndrome

Most of the studies have assured that the $S$. aureus as one of the infectious microbes in many patients which have polymicrobial infections [15]. S. aureus and the coexisting microbes interact with each other, like with Candida albicans, Enterococcus faecalis, Haemophilus influenza and influenza virus, or competitive, as with Pseudomonas aeruginosa, Streptococcus pneumoniae, Lactobacillus sp. and Corynebacterium sp. [16, 17]. If interactions are cooperative or competitive, $S$. aureus within a community behaves very differently with respect to its monomicrobial growth.

The ability to up-regulate the infectious factors under many stressful stimuli (host immune response or circulating antibiotics) is an important reason for enabling of $S$. aureus to continue in the bloodstream and also resist to move deep in tissues, and to form secondary infection. $S$. aureus can effectively able to stick to colonize of the skin and mucosa and it invades the bloodstream to destroy host immunological responses forming protection and develop resistance to several antibiotics. These resistant factors are called virulence determinants and it can be divided into cell-surfaceassociated (adherence) and secreted (exotoxins) factors. Although the availability of many antibiotics which is effective against wild-type strains $S$. aureus is a very successful and increasingly clinically important grampositive pathogen. In the first step of colonization and infection it is important that microbes will stick to cells and extracellular matrix [18]. Previous studies showed the ability of colonizing of $S$. aureus over the populations and in the oral cavity $[19,20]$.

Many healthy people are persistently or intermittently colonized with $S$. aureus at their oral cavity and thus are at increased risk for certain staphylococcal infections. Interestingly, there is now a growing body of evidence to suggest that staphylococci can be isolated frequently from oral cavity of particular patient groups such as children elderly and some groups with systemic disease such as the terminally ill, those with rheumatoid arthritis and patients with hematological malignancies $[8,9]$. The exact reasons for these differences in colonization patterns are yet unknown. A more recent study found that $64 \%$ of healthy children carried $S$. aureus in the oral cavity. Most studies sample the oral cavity by use of swabs, rinses and plaque scrapings and found staphylococci in plaque from the fissures of teeth [5].

Staphylococci require a combination of multiple virulent genes to cause infection [8]. These virulent factors encoding genes of Staphylococci may determine the pathogenesis process employed by this strain to cause infection.

Saliva in the oral cavity contains many antimicrobial enzymes such as lysozyme and secretary $\operatorname{IgA}$ to provide barrier to microbial colonization by $S$. aureus in the oral cavity [21]. These $S$. aureus strains carry different virulence factors that contribute to the development of the infectious process such as, adhesions, internalization and toxins. The general accepted hypothesis is that pathogenic Staphylococci strains evolved from non-pathogenic strains by acquiring new virulence factors from accessory DNA horizontal transfer located at the chromosomal or plasmid level.

The current study is therefore, undertaken to isolate and characterize staphylococci genotype from dental patients presented at Tehsil Head Quarter hospital Pasrur. The aim of the current study is to develop protocols for the successful isolation and confirmation of Staphylococcus aureus, assess the prevalence of Staphylococcus aureus genes fnbA \& fnbB along with antibiotic sensitivity pattern of these isolates

\section{MATERIALS AND METHODS}

\section{COLLECTION OF SAMPLES:}

Total of 100 samples were collected from dental patients attended outdoor patient department (OPD) of Tehsil Headquarter Hospital Pasrur, Pakistan. Three ml of dental Intracrevicular washing and scrapings fluid was collected from every patient with $2 \mathrm{~mm}$ size of hard dental plaque and shifted to $20 \mathrm{ml}$ sterile plastic container. Samples were stored at $4^{\circ} \mathrm{C}$ in a cool place and then transported to the laboratory (Fig. 1).

\section{SAMPLE SIZE:}

The sample size was calculated by using the formula of Kish \& Lisle states that [22]

$$
\begin{aligned}
& \mathrm{n}=\mathrm{z} 2 \mathrm{p}(1-\mathrm{p}) / \mathrm{d} 2) \\
& \text { Where, } \mathrm{z}=\text { Score for } 95 \% \text { confidence interval }=1.96 \\
& \mathrm{p}=\text { Prevalence } \\
& \mathrm{d}=\text { Sampling error that could be tolerate }=5 \% . \\
& 1-\mathrm{p}=\text { Probability }
\end{aligned}
$$

\section{ISOLATION OF THE BACTERIA:}

Specified grams of mannitol salt (MS) agar, nutrient agar, blood agar were weighed using digital balance (Shimadzu Scientific Instruments-Japan) and suspended in $1000 \mathrm{ml}$ glass flask containing distilled water according to manufacturer instructions (Oxoid Ltd- England). The suspension was sterilized by autoclaving at $121^{\circ} \mathrm{C}$ for 15 minutes. $20 \mathrm{ml}$ of 
each autoclaved nutritional media was poured on $9 \mathrm{~mm}$ disposable petri plate and subjected for incubation at $37^{\circ} \mathrm{C}$ for 48 hours. Loopful of saliva mixed gingival fluid and $100 \mu \mathrm{l}$ caries/ sulcus normal saline washing solution was streaked on the nutrient agar and MS agar. Cultures were incubated anaerobically for 48 hours at $37^{\circ} \mathrm{C}$. (Fig. 5)

\section{IDENTIFICATION OF ISOLATES:}

After the incubation period, the colonies were identified on the basis of colony morphology. The typical colonies from each sample plate were transferred to blood agar (Oxoid LtdEngland) for further purification and incubated anaerobically at $37^{\circ} \mathrm{C}$ for two days. The following steps were involved in identification and characterization of the isolates:

a. Colonial shape and form on MS-agar and Blood agar.

b. Gram-staining and microscopic examination.

c. Analytical profile index analysis

d. Antibiotic Susceptibility test

e. Molecular characterization through Polymerase chain reaction (PCR).

\section{GRAM STAINING:}

Every pure culture grown on the surface of selective medium showing standard characteristics colony were selected for Gram Staining. It was performed according to standard procedure. Smear was established by placing a loopful of culture on microscope glass slide re-suspended with drop of distilled water in circular pattern. The smear was fixed by passing 3-4 times on flame followed by heat air drying. Straining was performed according to the method described by Bergey (Fig. 6) [23].

\section{BIOCHEMICAL ASSAY}

Biochemical test were performed on the pure culture of isolates often getting significant growth on mannitol salt agar. A loop full of pure culture was mixed with the specific reagent followed by prescribed incubation time. Biochemical tests such as catalase and coagulase test were performed according to method described by Bergey's manual of systematic bacteriology [24].

DNA EXTRACTION:

All the samples including positive known bacteria were subjected for extraction of DNA by using QAIamp DNA Mini kit (QIAGEN-Germany) according to the manufacturer instructions. All the extracted DNA was separately stored in $1 \mathrm{ml}$ labeled eppendorf tubes at $-20^{\circ} \mathrm{C}$. These samples were subjected to molecular identification (Fig. 7).

\section{PCR IDENFICATION:}

The extracted DNA of all samples were subjected to PCR for amplification of the desired genes $f n b A, f n b B, 23 \mathrm{Sr}$ RNA and Nuc of $S$. aureus. The sequence of these primers were:

TABLE 2: Primer Sequences

\begin{tabular}{|c|c|c|c|}
\hline \multirow[b]{2}{*}{ S. aureus } & F Primer & $f n b \mathrm{~A}$ & GCGGAGATCAAAGACAA \\
\hline & R Primer & fnbA & CCATCTATAGCTGTGTGG \\
\hline \multirow[b]{2}{*}{ S. aureus } & F Primer & $f n b \mathrm{~B}$ & GGAGAAGGAATTAAGGCG \\
\hline & $\mathrm{R}$ Primer & $f n b \mathrm{~B}$ & GCCGTCGCCTTGAGCGT \\
\hline \multirow{2}{*}{ S. aureus } & F Primer & Nuc & GCGATTGATGGTGATACGGTT \\
\hline & R Primer & $N u c$ & AGCCAAGCCTTGACGAACTAAGC \\
\hline
\end{tabular}

\begin{tabular}{llll}
\hline \multirow{3}{*}{ S. aureus } & F Primer & $\begin{array}{l}\text { 23SrR } \\
\text { NA }\end{array}$ & ACGGAGTTACAAAGGACGAC \\
\cline { 2 - 4 } & R Primer & $\begin{array}{l}\text { 23SrR } \\
\text { NA }\end{array}$ & AGCTCAGCCTTAACGAGTAC \\
\hline
\end{tabular}

For the PCR reaction, $2 \mu 1$ of $10 \mathrm{X}$ PCR buffer, $1 \mu 1$ of forward and reverse primer, $2 \mu 1$ of $80 \mathrm{mM} \mathrm{MgCl} 2,2 \mu \mathrm{l}$ of DNTPs mixture and $1 \mu \mathrm{l}$ of Taq DNA polymerase (PerkinElmer Cetus, Norwalk, Conn.) were added to the reaction mixture. Reaction volume was obtained by adding $9 \mu$ of Nuclease-free Water and $2 \mu 1$ of extracted DNA sample. The PCR tubes were incubated in thermal cycler (Applied Biosystems) with an initial denaturation of $94^{\circ} \mathrm{C}$ for 2 minutes followed by 30 cycles of denaturation at $94^{\circ} \mathrm{C}$ for 30 seconds, annealing at $50^{\circ} \mathrm{C}, 50^{\circ} \mathrm{C}, 55^{\circ} \mathrm{C}, 60^{\circ} \mathrm{C}$ for 30,60 seconds and extension at $72^{\circ} \mathrm{C}$ for 60 seconds. Final extension was conducted at $72^{\circ} \mathrm{C}$ for 5 minutes. (Fig. 7)

PCR product was analyzed by electrophoresis in $1 \%$ agarose gel using TAE buffer (pH-8). A 1000bp DNA ladder was included in each gel. The DNA was stained with $0.5 \mu 1$ ethidium bromide and visualized under UV illuminator. (Fig. 8)

\section{ANTIBIOTIC SUSCEPTIBILITY TESTING OF BACTERIAL ISOLATES:}

Antibiotic susceptibility test of the clinical isolates was done using modified Kirby-Bauer disc diffusion method in accordance with the guidelines of the Clinical and Laboratory Standards Institute [25]. The antibiotics used in this study include Oxacillin, Ciprofloxacin (CIP), Erythromycin (E), Vancomycin (VA), Clindamycin (CD), Gentamycin (G), Tmp-Smx, Fusidic acid and Linezolid. The antimicrobial combinations used were $\mathrm{AMC}$ and $\mathrm{AM} /$ sulbactam $(\mathrm{A} / \mathrm{S})$. Bacterial inoculums were prepared by suspending the freshly grown bacteria in $2 \mathrm{ml}$ of sterile brain heart infusion broth with yeast extract, and the turbidity of tube was matched with $0.5 \mathrm{McF}$ arland turbidity standards and then swabbed onto Mueller-Hinton agar plate. To prevent condensation, antibiotic discs were allowed to warm to ambient temperature before application. Within $15 \mathrm{~min}$ of inoculation, the antibiotic discs were placed at side down on the seeded agar surfaces using sterile forceps, followed by incubating agar plates for 24 hours at $37^{\circ} \mathrm{C}$. The relative susceptibility of the bacterial growth to each antibiotic shown by a clear zone of inhibition was measured in $\mathrm{mm}$ and zone diameter criterion was used to interpret the level of susceptibility to each antibiotic (Fig. 9).

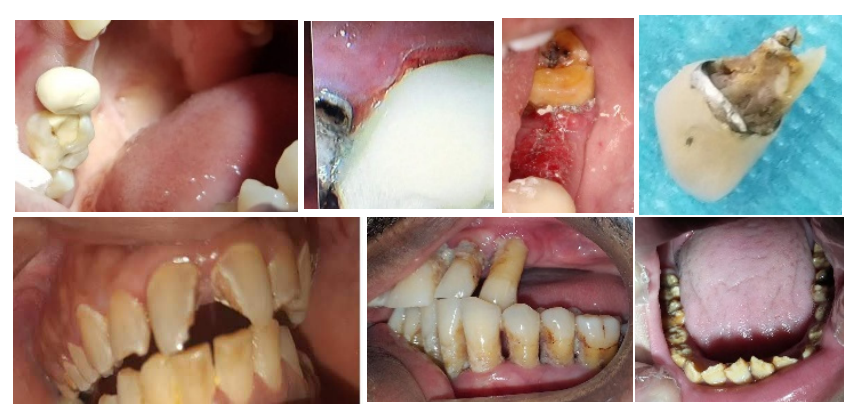

Fig. 1: Collection of intracrevicular washing and scrapings fluid from dental patients 


\section{RESULTS}

Caries is a polymicrobial infection and every bacterial species plays a role in determining the carcinogenicity of the biofilm or dental plaque. Out of 100 samples, 68\% yellow colonies upto $1 \mathrm{~mm}$ diameter on mannitol salt agar recovered form saliva mixed gingival fluid of caries active patients were declared as staphylococcal species. Gram staining of such colonies showed $68 \%$ round in shape forming cluster having purple color in compound microscope. The colonies showing beta hemolysis on blood agar were selected and streaked on Mueller-Hinton agar media for antibiotic susceptibility pattern. Biochemical assay analysis revealed that $60 \%$ colonies are positive for catalase and coagulase. Molecular characterization of staphylococcus species isolated from dental patient showed $0 \%, 0 \%, 47 \%$ and $23 \%$ percentage positivity of fnbA, fnbB, 23SrRNA and NUC respectively.

In male caries active patients, biochemical analysis revealed that $32(54.3 \%)$ samples were positive for Staphylococci subsequently to high prevalence for 23SrRNA gene $30(50 \%)$ followed by NUC, fnbA and fnbB genotype of S. aureus $15(25 \%), 0(0 \%)$ and $0(0 \%)$ respectively. Moreover, 27 (67.5\%) samples of female dental patients with active caries were screened for significant bacterial count and identified as Staphylococcus in biochemical analysis. The frequency of 23SrRNA, NUC, fnbA and fnbB genotype sequence of S. aureus $17(42.5 \%), 8(20 \%), 0(0 \%)$ and $0(0 \%)$ respectively.

The prevalence of 23SrRNA sequence of S. aureus in dental patients based on age group indicates that individuals of the age 40-60 year age had high incidence (48.2\%) than age group 10-20 years (47.6\%) and 20-40 years (46\%) through PCR analysis. The prevalence of S. aureus specific NUC amplicon were detected higher (28\%) in patients of 20 40 years age group as compare to (24.8\%) 10-20 year age and (24.1\%) 40-60 year age respectively. There was no amplification of adhesive genes fnbA and fnbB of S. aureus in any of three age group.

Kirby-Bauer disc diffusion analysis of clinical isolates against 9 commercially used antimicrobial drugs in industry. All isolates were sensitive against oxacillin, ciprofloxacin, fusidic acid, clindamycin, gentamycin, erythromycin, linezolid, Tmp-smx and vancomycin to staphylococcus isolates was $67.7 \%, 66.1 \%, 79.6 \%, 84.7 \%, 76.2 \%, 59.3 \%$, $98.3 \%, 57.6 \%$ and $100 \%$ respectively.

Whereas, oxacillin, ciprofloxacin, fusidic acid, clindamycin, gentamycin, erythromycin, linezolid, Tmp-smx and vancomycin showed percentage resistance to staphylococcus isolates was $32.3 \%, 34.9 \%, 40.7 \%, 42.4 \%$, $24.8 \%, \quad 20.4 \%, \quad 15.3 \%, \quad 1.7 \%, \quad 0.0 \% \quad$ respectively. Combinations were used with an objective to broaden the spectrum of antimicrobial action. Among the antimicrobial combinations used, the greatest potency was shown by A/S followed by AMC. Among these antibacterial drugs tested, vancomycin showed maximum zone of inhibition followed by trimethoprimsulphamethaxazole (57.6\%) (Fig. 4).

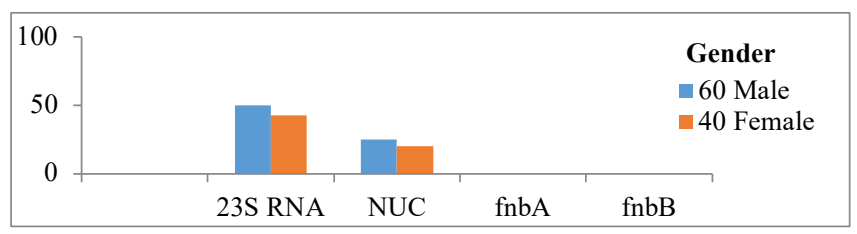

Fig. 2: Gender based prevalence of adhesion genes

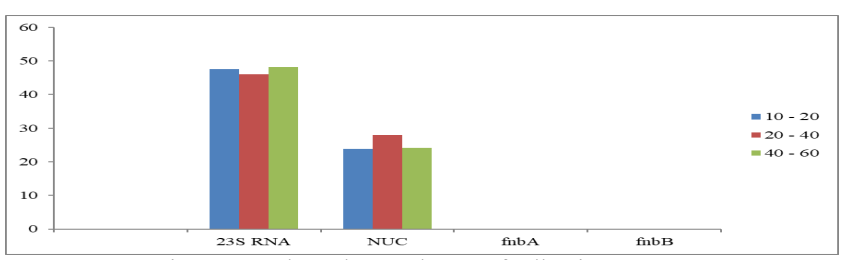

Fig. 3: Age based prevalence of adhesion genes

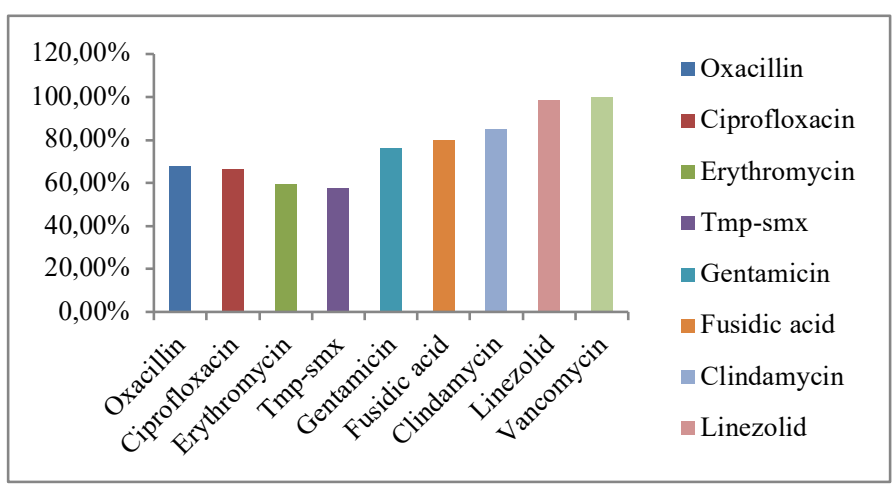

Fig. 4: Percentage of sensitivity pattern of S. aureus

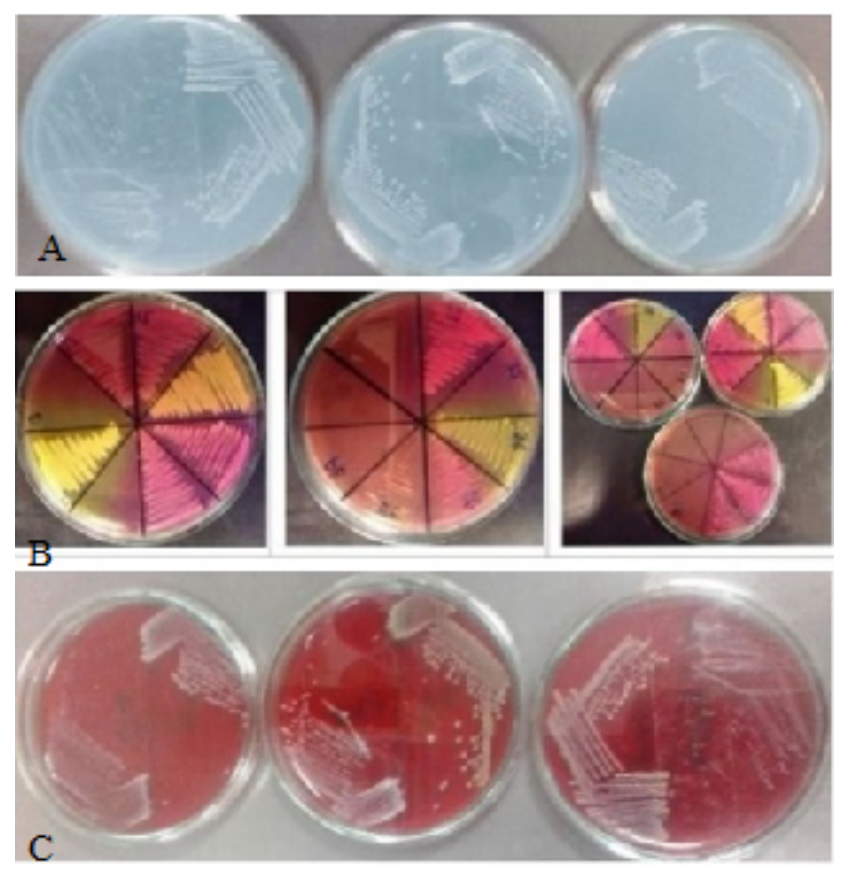

Fig. 5: Isolation and growth of bacteria on Selective Medium

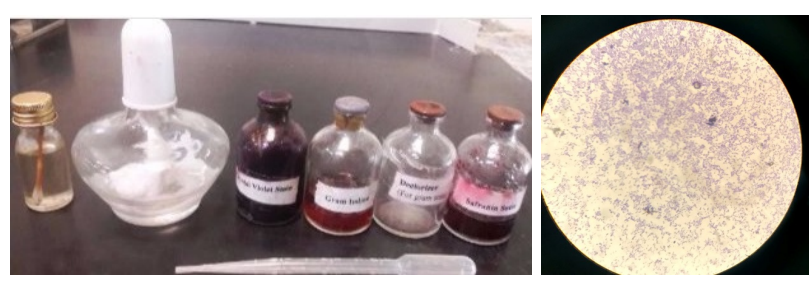


Fig. 6: Gram Staining and Microscopy

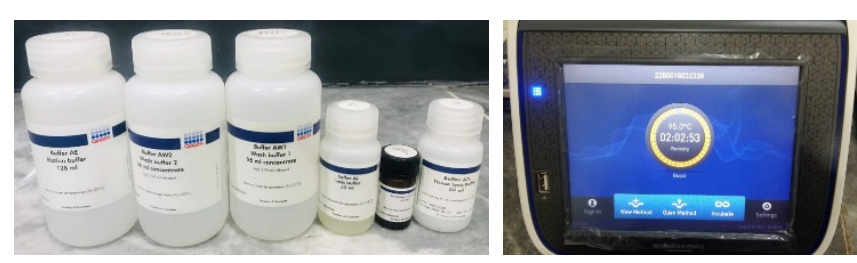

Fig. 7: DNA Extraction and Polymerase Chain Reaction
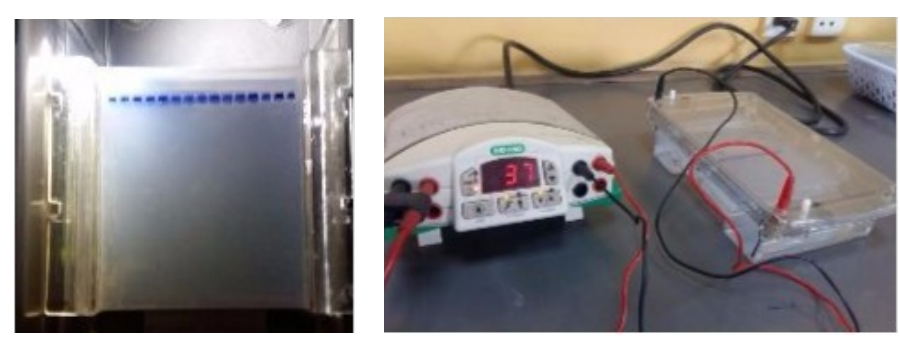

Fig. 8: Gel Electrophoresis

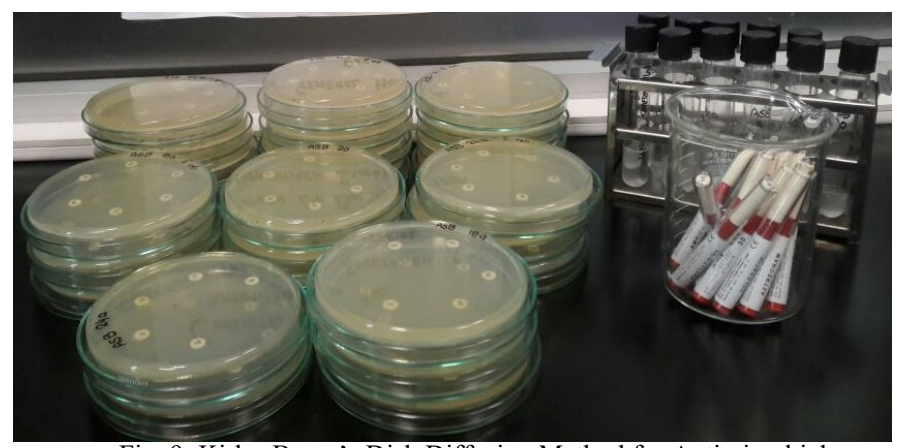

Fig. 9: Kirby-Bauer's Disk Diffusion Method for Antimicrobial Susceptibility Test

\section{DISCUSSION}

In the present study bacterial isolates recovered from dental patients were confirmed for Staphylococcus aureus by using conventional microbiological techniques such as cultivating pure culture on blood agar and Mannitol Salt agar, typical colony characteristics such as form, shape, color, consistency and hemolysis pattern, microscopic features includes gram positive cocci arranged in clusters and confirmatory biochemical reactions of catalase and coagulase. The name aureus showed that the colonies are produced on solid media have a golden color, which is due to the presences of carotenoids in opposition to the pale, translucent white colonies produced by CoNS $[26,27]$. S. aureus is part of the natural microbiota found in the ecology of oral cavity, including MRSA. Total of bacterial isolates showed positive for catalase test (60\%), coagulase test $(59 \%)$ and found with same percentage distribution. The results of the current study corroborates with the findings of Koneman who reported that $(69 \%)$ of isolates were catalase positive and $(63 \%)$ were coagulase positive [28]. It was also observed that PCR based analysis amplified amplicon size of $1250 \mathrm{bp}$ and 279bp for 23 srRNA and NUC gene of Staphylococcus aureus respectively. $47 \%$ and $23 \%$ of samples were found positive for S. aureus specific primers of 23sRNA and NUC genes respectively. Whereas, there was no amplification found for fnbA and fnbB genes among all S. aureus isolates. In this study Genotypic prevalence of $23 \mathrm{~S}$ RNA of S. aureus was significantly higher $47 \%$ as compared to nuc $23 \%$. The results are in partial agreement with Dimitar Nashev who reported that incidence of 23S rRNA encoding gene and thermonuclease NUC gene are significantly higher in selected dental patients [29]. The results of current study do not agree with Mongodin who revealed that major role of fnbPs in S. aureus is adherence to human airway epithelium, whereas Staphylococcal protein A and clumping factor did not play any role in this process [30]. These authors also reported that $97 \%$ of 32 clinical strains, isolated from the airway secretions of patients with cystic fibrosis and nosocomial pneumonia, possessed the two fnb genes. Thus, the presence of these genes seems to be an important factor for microbial pathogenesis. Both investigated different $\mathrm{S}$. aureus lineages associated with various sites of infection and showed that $89.7 \%$ of the isolates, regardless of lineage identity, possessed gene fnbA, whereas fnbB was observed in $20.1 \%$ of the isolates. The latter was present only in the lineage associated with blood isolates. Peacock showed that $98 \%$ of invasive isolates harbored fnbA versus $87 \%$ in the carriage group [31]. The difference in observation may be due to the selection of sample size, variation in techniques used for the isolation of bacteria from the morbid samples and socio-economic status of the patients selected in both of the studies.

The ability to form biofilms is an important virulence factor in Human disease of S. aureus [32]. Biofilm found to facilitate the stickiness and colonization of Staphylococci on the mammary gland epithelium [30]. A known characterized family of Staphylococcal surface adhesions, Called MSCRAMMs (microbial surface components recognizing adhesive matrix molecules) are known to adherence to host extracellular matrix components such as fibronectin and collagen [33]. Combining to fibronectin is done by two closely related proteins, FnBPA and FnBPB, which is encoded by the genes fnbA and fnbB [34]. FnBPs moderate adhesion of $\mathrm{S}$. aureus to human epithelial cells, including many airway epithelium, endothelial cells and fibroblasts which may cause an internalization of the bacteria in the many cells [35]. FnBPA and FnBPB are necessary for bacterial adhesion to fibronectin- coated surfaces. However, fnbA or fnbB deficient single mutants represented no significant reduction in their adhesive properties, whereas the two mutants were completely losses the ability to adhere and $\mathrm{S}$. aureus isolates from the associated diseases, including endocarditis, primary septic arthritis and osteomyelitis were more likely to have both genes fnbA and fnbB [36, 37]. CNA of S. aureus was defined as virulence factor in septic arthritis and osteomyelitis [38]. Previously, it was detected the presence of 33 infectious disease of S. aureus and found that the genes fnbA and CNA were significantly more common in invasive isolates [40]. In contrast to the relatively wellstudied adherence mechanisms and surface components of S. aureus invasive isolates, the studies concerning the adhesive molecules in persistently or intermittently colonizing nasal mucosa strains are still limited in number [41]. In current study non-significant differences were observed between gender and age associated prevalence used for the estimation of Staphylococcus aureus genotypes harbors in the oral cavity of dental patients. It was recorded that Staphylococcus genotype 23SrRNA and NUC in age range between 10-20 years old patients was comparatively higher than age range 20-30 years old dental patients. Whereas, samples obtained from dental patients fall in range between 10-20 years showed 
significantly higher prevalence of Staphylococcus genotype 23SrRNA and NUC as compared with patients of 30-40 years of age. The results are in lines with the observations of Guentsch A. who reported significantly higher prevalence in younger children of age in range between 10-20 years [42]. High incidence of Staphylococcus aureus in younger children is may be due to the excessive consumption of sugars which are decomposed by the dental flora resulting increase in acid production and drop in $\mathrm{pH}$. The whole process will start demineralization and formation of biofilm on the crown of teeth. In this study, we observed multiple drug resistance in $\mathrm{S}$. aureus isolates of oral dental swabs and rinsed samples of affected teeth. The antibiogram results revealed that vancomycin, linezolid and clindamycin showed highest sensitivity in terms of zone of inhibition towards Staphylococcus aureus isolated from dental patients. Moreover, penicillin did not show any inhibition S. aureus isolates on Muller Hilton agar plate and declared as resistant. Results are in agreement with finding of Hanif who recorded that penicillin is resistant against local isolates of $\mathrm{S}$. aureus [43]. In the present study the data of antimicrobial susceptibility suggest that all drugs have shown reduced sensitivity against Staphylococcus except chloramphenicol and trimethoprim-sulphamethaxazole that may be because of injudicious use of these antibiotics in the community.

\section{REFERENCES}

[1] MJ Wilson, WG Wade. Application of molecular ecology in the characterization of uncultured microorganisms associated with human disease. Rev Med Microbiol. Vol 8, pp. 91-101,1997.

[2] TW MacFarlance, SJ Helnarska. The microbiology of angular cheilitis. Br Dent J. Vol 140, pp. 403-406,1976.

[3] AY Kaufman, EF Henig. The microbiologic approach in endodontics. Oral Surg Oral Med Oral Pathol. Vol 42, pp. 810-816,1976.

[4] TP Wyman, WE Dowden, K Langeland. Staphylococcus aureus isolation from a clinically not exposed root canal. J Endodont. Vol 4, pp. 122-128,1987.

[5] GF Koorbusch, P Fotos, KT Goll. Retrospective assessment of osteomyelitis, Etiology, demographics and management in 35 cases. Oral Surg Oral Med Oral Pathology. Vol 74, pp. 149-154,1992.

[6] MH Goldberg, Infection of the salivary gland. In: Topazian RG, Goldberg $\mathrm{MH}$ (eds) Management of infections of the oral and maxillofacial region. Pheladelpheia, WB Saunders. pp. 293-311,1981.

[7] J Bagg, MP Sweeney, K Harvey-wood, A Wiggings. possible role of staphylococcus aureus in several oral mucositis among elderly dehydrated patients. Microb Ecol Health Dis. Vol 8, pp. 51-56,1995.

[8] Y Miyake, M Iwai, M Sugai, K Miura, H Suginaka, N Nagasaka. Incidence and characterization of staphylococcus aureus from the tongues of children. J. Dent Res. Vol 70: pp. 1045-1047,1991.

[9] J Jobbins, J Bagg, K Parsons, I Finlay, M Addy, RG Newcombe. Oral carriage of yeasts, coliforms and staphylococci in patients with advanced malignant disease. J Oral Pathol Med. Vol 21, pp. 305308,1992 .

[10] JJ Jacobson, B Patel, G Asher, JO Wooliscroft, D Schaberg. Oral staphylococcus in older subjects with rhematoids arthritis. J. AM. Geriat Sco. Vol 45, pp. 590-593,1997.

[11] MS Jackson, J Bagg, H Kennedy, J Michie. Staphylococci in the oral flora of healthy children and those receiving treatment for malignant disease. Microb Eco Health Dis. Vol 12, pp. 60-64,2000.

[12] WE Klos and TL Bannerman. Update on clinical significance of coagulase-negative staphylococci. Clinical microbiology Reviews. Vol 79, Issue 1, pp. 117-140,1994.

[13] KB Crossley and GL Archer. The staphylococci in human disease, Churchill Livingstone, 1997. pp. 682

[14] J Kluytmans, A Van Belkum and H Verbrugh. Nasal carriage of Staphylococcus aureus: epidemiology, underlying mechanism and associated risks. Clinical Microbiology Reviews.1997; Vol 10, Issue 3 , pp. 505-520,1997.

[15] L Finelli, A Fiore, R Dhara, L Brammer, DK Shay, L Kamimoto, A Fry, J Hageman, R Gorwitz, J Bresee, T Uyeki. Influenza associated pediatric mortality in the united states: increase of Staphylococcus aureus coinfection. Pediatrics. Vol 122, pp. 805-811,2008.
[16] SA Madhi, P Adrian, L Kuwanda, C Cutland, WC Albrich, KP Klugman. Long term effect of pneumococcal conjugate vaccine on nasopharyngeal colonization by Streptococcus pneumoniae and associated interactions with staphylococcus aureus and Haemophilus influenza colonization in HIV infected and HIV uninfected children. J. Infe. Dis. Vol 196, pp. 1662-1666,2007.

[17] BS Gan, J Kim, G Reid, P Cadieux, JC Howard. Lactobacillus fermentum RC-14 inhibits Staphylococcus aureus infection of surgical implants in rats. J. Inect. Dis. Vol 185, pp. 1369-1372,2002.

[18] J Kluytmans, A Van Belkum, H Verbrugh. Nasal carriage of Staphylococcus aureus: epidemiology, underlying mechanism and associated risks. Clin Micro Rev. Vol 10, pp. 505-520,1997.

[19] R Wenzel, T Pearl. The significance of nasal carriage of Staphylococcus aureus and the incidence of postoperative wound infection. J Hosp Infect. Vol 31, pp. 13-24,1995.

[20] K Toshkova, C Annemculler, C Lammler. The significance of nasal carriage of Staphylococcus aureus as risk factor for human skin infection. FEMS Microb. Lett. Vol 202, pp. 17-24,2001.

[21] AJ Smith, MS Jackson and J Bagg. Ecology of staphylococcal species in the oral activity. J. Med. Micro. Vol 50, pp. 940-946,2001.

[22] Kish, Leslie. Survey Sampling. New York: John Wiley and Sons, Inc, 1965.

[23] Bergey, G John, Holt, R Noel, Krieg, HA Peter, Sneath. Bergey's Manual of Determinative Bacteriology, 9th ed. Lippincott Williams \& Wilkins, 1994.

[24] JG Holt, NR Krieg, PHA Sneath, JT Staley, ST Williams. Bergeys manual of determinative bacteriology edited by William R Henayl, (Lippincott Williams \& Wilkins, New York) 2000, pp. 296

[25] AW Bauer, WM Kirby, JC Sherris, M Turck. Antibiotic Susceptibility Testing by a Standardized Single Disk Method. American Journal of Clinical Pathology. Vol 45, pp. 493-496,1966.

[26] BJ Howard and WE Kloos. Staphylococci, in: BJ Howard, J Klass, J RS, AS Weissfeld and RC Tilton (Eds). Clinical and pathogenic Microbiology, Mosby, Washington, pp. 231-234,1987.

[27] GY Liu, A Essex, JT Buchanan, V Datta, HM Hoffman, JF Bastian, J Fierer and V Nizet. Staphylococcus aureus golden pigment impairs neutrophil killing and promotes virulence through its antioxidant activity. The Journal of Experimental Medicine. Vol 202, Issue 2, pp. 209-215,2005.

[28] EWAS Koneman, WM Janda, PC Schreckenberger, WC Winn, et al; The gram positive cocci: Staphylococci and related organisms. In color Atlas and textbook of diagnostic Microbiology. Philadelphia: Lippincott- RavenKoneman EW. Vol 5, pp. 55-576,1977.

[29] D Nashev, K Toshkova, S Isrina, O Salasia, AH Abdulwahed. Distribution of virulence genes of Staphylococcus aureus isolated from stable nasal carries. FEMS Microbiology Letters. Vol 233, pp. 45-52,2004.

[30] E Mongdin, O Bajolet, J Cutrona, N Bonnet, F Dupuit, E Puchelle and $\mathrm{S}$ DeBemtzmann. Fibronectin-binding protein of Staphylococcus aureus are involved in adherence to human airway epithelium. Infect. Immun. Vol 70, pp. 620-630,2002.

[31] S Peacock, C Moore, A Justice, M Kantazanou, L Story, K Mackie, G Neil and N Day. Virulent combinations of adhesion and toxin genes in natural populations of Staphylococcus aureus. Infect. Immun. Vol 70, pp. 4987-4996,2002.

[32] BN Doebbeling. Nasal and hand carriage of Staphylococcus aureus in healthcare workers. J Chemotherapy. Vol VI, Issue 2, pp. 1117,1994 .

[33] W Naverre, O Schneewind. Surface protein of gram positive bacteria and mechanism of their targeting to the cell wall envelop. Microbiol Mol Biol Rev. Vol 63, pp. 174-229,1999.

[34] J Flock, G Fromann, K Jonsson, B Guss, C Signas, B Nilsson, G Raucci, M Hook, T Wadstrom, M Lindberg. Cloning and expression of the gene for a fibronectin-binding protein from staphylococcus aureus. EMBO J. Vol 6, pp. 2351-2357,1987.

[35] K Dziewanowska, J Patti, Cc Deobald, K Bayles, W Trumble and G Bonach. Fibronectin binding protein and host cell tyrosin kinase are required for internalization of staphylococcus aureus by epithelial cells. Infect. Immun. Vol 67, pp. 4673-4678,1999.

[36] C Greene, D McDevitt, P Francois, P Vaudaux, D Lew, T Foster. Adhesion properties of mutants of Staphylococcuss aureus defective in fibronectin- binding proteins and studies on the expression of fnb fenes. Microbiol. Vol 17, pp. 1143-1152,1995.

[37] S Peacock, N Day, M Thomas, A Berendt, T Foster. Clinical isolates of Staphylococcus aureus exhibit diversity in fnb genes and adhesion to human fibronectin. J Infect. Vol 41, pp. 23-31,2000.

[38] L Switalski, J Patti, W Butcher, A Gristina, P Speziale, M Hook. A collagen receptor on Staphylococcus aureus strains isolated from patients with septic arthritis mediates adhesion to cartilage. Mol Microbiol. Vol 7, pp. 99-107,1993. 
[39] M Elasri, J Thomas, R Skinner, J Blevins, K Beenken, C Nelson, M Smelterz. Staphylococcus aureus collagen adhesion contributes to the pathogenesis of osteomyelitis. Bone. Vol 30, pp. 275-280,2002.

[40] S Peacock, C Moore, A Justice, M Kantazanou, L Story, K Mackie, G Neil and N Day. Virulent combinations of adhesion and toxin genes in natural populations of Staphylococcus aureus. Infect. Immun. Vol 70, pp. 4987-4996,2002.

[41] A Van Belkum, NH Riewarts Eriksen, M Sijmons, W Van leeuwen, M Van den Bergh, J Kluytmans, F Espersen, H Verbrugh. Coagulase and protein A polymorphisms do not contribute to persistence of nasal colonization by Staphylococcus aureus. J Med Microbiol. Vol 46, pp. 222-232,1997.

[42] A Guentsch, M Puklo, PM Preshaw. Neutophils in chronic and aggressive periodontitis in interaction with Porphyromonas gingivalis ans Aggregatibacter actinomycetemcomitans. J Periodonatal Res. Vol 44, pp. 368-377,2009.

[43] MM Hanif, T Butt, M Amjad. Pathogens involved and antibiotic sensitivity pattern of isolates in community acquired common bacterial skin infections presenting in tertiary care hospital. Pak. Arm. Forces Med. J.Vol 3, pp. 289-294, 2006.

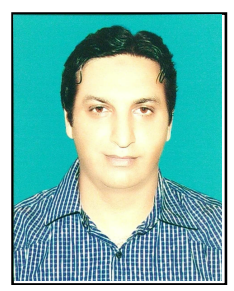

Dr. Muhammad Danish Mehmood

02-01-1980

DVM, UVAS, Pakistan

Ph.D. Microbiology, The University of Lahore, Pakistan 